\title{
12
}

\section{Linking Integrated Coastal Zone Management to Maritime Spatial Planning: The Mediterranean Experience}

\author{
Emiliano Ramieri, Martina Bocci, and Marina Markovic
}

\section{Introduction to the Mediterranean Basin}

The Mediterranean Sea is the largest semi-enclosed sea in the world, stretching $4,000 \mathrm{~km}$ from east to west, with a maximum width of $800 \mathrm{~km}$. Its coastline is approximately $46,000 \mathrm{~km}$ long, with nearly $19,000 \mathrm{~km}$ of island coastline (UNEP/MAP-Plan Bleu 2009). The mean depth of the Mediterranean Sea is $1,370 \mathrm{~m}$, while the maximum is around $5,267 \mathrm{~m}$ (recorded at Calypso Deep, Greece). It is connected to the Atlantic Ocean through the Strait of Gibraltar. The Dardanelles, Marmara Sea and the Bosporus Strait connect it to the Black Sea, and the Suez Canal connects it to the Red Sea. The main rivers bringing significant water flow to the Mediterranean Sea are the Rhone, Po, Nile and Ebro Rivers (Saliot 2005).

Marine waters fall into different legal regimes, as defined by the United Nations Convention on the Law of the Sea (UNCLOS): internal waters, territorial sea, contiguous zone, Exclusive Economic Zones (EEZs), continental

E. Ramieri $(\bowtie) \cdot$ M. Bocci

Thetis SpA, Venice, Italy

e-mail: emiliano.ramieri@thetis.it

M. Markovic

UNEP/MAP PAP/RAC, Split, Croatia 
shelf and high seas. Delimitation of maritime boundaries in the Mediterranean is complex, mainly due to geographical, geopolitical and economic reasons, and requires complex agreements among neighbouring states. This results in several yet unsolved issues even with respect to territorial sea borders. Most Mediterranean states have established a 12-mile territorial sea, while declaration of EEZs through the adoption of the national legislation has been carried out only by some Mediterranean states (MRAG, IDDRA, and LAMANS 2013; DOALOS 2018). In addition, "EEZ derived zones", such as fisheries zones, fisheries protection zones, ecological protection zones and ecological and fishery protection zones, have been declared through national legislation by a number of states; however, these zones encompass only some of the rights that can be exercised within the EEZ. It should also be noted that claim for EEZs and "derived" zones, based on adopted national legislation, does not automatically lead to their full validation and implementation. Although the first formal step for the establishment and delimitation of a maritime zone is the adoption of legislation in the form of law, a number of additional steps are necessary before the final validation of the claimed zone and its boundary (MRAG, IDDRA, and LAMANS 2013; DOALOS 2018). Unlike the EEZ, a coastal state does not need to declare its continental shelf, as its existence is inherent. However, its delimitation (in line with art. 77 of UNCLOS) is often done in agreement with the neighbouring states. In the Mediterranean, there are some delimitation issues still pending also related to the continental shelf (Chevalier 2004). Taking into account the above-mentioned status of EEZs and "derived" zones, more than $20 \%$ of the marine waters in the Mediterranean fall under a high seas regime governed by international norms (Cinnirella et al. 2014). This limits interventions of coastal states in economic and environmental maritime affairs and calls for strong cooperation at the regional level.

Cooperation is particularly relevant for the preservation of natural and environmental conditions that are the basis for various economic activities and social benefits of Mediterranean states. Known as a biodiversity hotspot, the Mediterranean is rich in endemic flora and fauna, with biodiversity representing between $4 \%$ and $18 \%$ of all the marine species known worldwide (Piante and Ody 2015). Richness of species and habitats lead to outstanding aesthetic value which (apart from other values such as cultural heritage) represents a vital resource for tourism development. However, intensified coastal and maritime activities (including tourism) are often responsible for loss of biodiversity. To date, nearly $19 \%$ of assessed species are considered threatened by extinction (UNEP/MAP-Plan Bleu 2009). 
Moreover, according to the analysis carried out by the MEDTRENDS project (Piante and Ody 2015), almost all Mediterranean maritime sectors (such as tourism, shipping, aquaculture, offshore oil and gas), except professional fisheries, are expected to grow during the next 15 years. Emerging sectors, such as renewable energy, seabed mining and biotechnology, are expected to grow even faster, although in absolute terms they will be less relevant than more traditional uses also in the future, and there is greater uncertainty on their possible evolution. Such growing development can increase existing conflicts between sectors and generate new ones; in addition, it will represent additional pressure on already stressed Mediterranean ecosystems. It also calls for strengthening collaboration among the countries, in order to ensure:

- reduction of overfishing and improvement of sustainable management of fish resources;

- management of maritime traffic specifically in congested or strategically important areas (e.g. the Adriatic Sea, the Aegean Sea and the connection to the Black Sea, the routes connecting to the Suez Canal, Gibraltar Strait);

- reduction of risk of ship collisions and environmental accidents; and

- management of conflicts that might arise from the exploitation of submarine natural gas and oil resources.

Having in mind the existing threats to the marine environment and the migratory nature of marine species, collaboration between the Mediterranean countries is particularly important for achieving Good Environmental Status (GES) of the sea. Therefore, the ongoing shift from habitat conservation approaches to biodiversity and ecosystem functioning approaches, beyond national boundaries, reflects much better the rationale which sustains the management and conservation of marine ecosystems. This shift calls for holistic, integrative and ecosystem-based frameworks (UNEP/ MAP 2017).

Beyond this introduction, this chapter is structured into four sections. The following one illustrates policies supporting coastal and marine planning in the Mediterranean Sea, referring, in particular, to the cooperation framework of the Barcelona Convention. Section 3 discusses links between Integrated Coastal Zone Management (ICZM) and Maritime Spatial Planning (MSP) in this sea basin and the important role played by land-sea interactions (LSI); examples of practices are provided in Sect. 4. Finally, some elements that can support the future integration of ICZM and MSP in the Mediterranean Sea 
are provided. Part of the contents of this chapter is based on initial results and outputs of the ongoing SUPREME and SIMWESTMED projects (co-funded by the European Union [EU] through the EC-DG Maritime Affairs and Fisheries) to which the authors of the chapter directly contributed.

\section{The Policy Frame for Coastal and Marine Planning and Management in the Mediterranean}

The Convention for the Protection of the Marine Environment and the Coastal Region of the Mediterranean (Barcelona Convention; signed in 1976; amended in 1995) is the main policy achievement of the Mediterranean Action Plan (MAP) of the United Nation Environment Programme (UNEP). The contracting parties to the Barcelona Convention are 21 countries bordering the Mediterranean Sea (Albania, Algeria, Bosnia and Herzegovina, Croatia, Cyprus, Egypt, France, Greece, Israel, Italy, Lebanon, Libya, Malta, Monaco, Montenegro, Morocco, Slovenia, Spain, Syria, Tunisia and Turkey) together with the EU. The Barcelona Convention is the only regional, legal and regulatory framework for the protection of the entire Mediterranean marine and coastal environment providing for objectives and obligations agreed by all the contracting parties:

- "to prevent, abate, combat and to the fullest extent possible eliminate pollution of the Mediterranean Sea Area" and

- "to protect and enhance the marine environment in that area so as to contribute towards its sustainable development" (Barcelona Convention, art. 4).

The Barcelona Convention is complemented by seven protocols (LandBased Source Protocol, Hazardous Wastes Protocol, Prevention and Emergency Protocol, Dumping Protocol, Offshore Protocol, Specially Protected Areas/ Biological Diversity Protocol and ICZM Protocol) and a number of strategies and plans (UNEP/MAP 2015). In addition to the legal framework, MAP contributed in setting out an institutional framework for cooperation addressing common marine and coastal challenges. The MAP Coordinating Unit and its Regional Activity Centres (RACs) are acting as a technical mechanism assisting the Mediterranean governments to implement their respective commitments for the protection of the marine and coastal environment. Standing out, for more than 40 years, as a coherent legal and institutional framework 
of cooperation, the Barcelona Convention system is a platform that contributes to building trust among Mediterranean countries in the joint actions towards planning and management of marine and coastal activities.

The Ecosystem Approach (EcAp) represents the overarching guiding principle to all policy implementation and development undertaken under the auspices of the Barcelona Convention. EcAp is to be integrated in all of the Convention's policies and activities, as it makes explicit the links between the status of natural resource systems and the services they provide. It also seeks to maintain the integrity and functioning of ecosystems as a whole, and recognises that the impacts of human activities are a matter of social choice. In the context of MAP, EcAp refers to a specific process, as the contracting parties have committed to implementing the EcAp with the ultimate objective of achieving GES of the Mediterranean Sea and coast. They do so through informed management decisions, and based on integrated quantitative assessment and monitoring of the marine and coastal environment of the Mediterranean. Decision IG.21/3 (UNEP(DEPI)/MED IG.21/9; the socalled EcAp Decision) expresses the agreement on regionally common targets and lists of indicators to achieve GES in the Mediterranean.

The EcAp process under the Barcelona Convention shares many commonalities with the process of implementation of the EU Marine Strategy Framework Directive (MSFD; Directive 2008/56/EC) (EC 2008a): for example, achieving GES and Healthy Environment which are independent of national jurisdictional waters. Both aim to establish a Programme of Measures to achieve their respective goals by 2020 . The subregional initial assessment prepared by MAP under the EcAp framework has been directly relevant to Mediterranean EU member states in their initial assessment required under MSFD. Even if MSFD is not applicable to the entire Mediterranean, its philosophy and principles could, nonetheless, be applied to the whole marine Mediterranean domain through the development of a shared vision via MAP. Both the MSFD and the MAP EcAp processes are committed to seeking mutual collaboration for the protection of the Mediterranean marine environment. However, there are important differences in the capacity for implementing specific measures or initiatives, with the implementation of such goals driven by different visions and concerns between different jurisdictions.

Planning of coastal and maritime activities is clearly taken on board by the Barcelona Convention and some of its protocols, primarily the Protocol on ICZM in the Mediterranean (UNEP/MAP/PAP 2008). Entered into force in 2011, the ICZM Protocol was a major innovation being the first (and still only) supranational legal instrument for coastal zone management (Rochette et al. 2012). ICZM is defined by the Protocol as a "dynamic process for the 
sustainable management and use of coastal zones, taking into account at the same time the fragility of coastal ecosystems and landscapes, the diversity of activities and uses, their interactions, the maritime orientation of certain activities and uses and their impact on both the marine and land parts." (ICZM Protocol, art. 2f). Spatial planning of coastal zones is an essential component of the ICZM Protocol, as one of the main objectives of ICZM is to "facilitate, through the rational planning of activities, the sustainable development of coastal zones by ensuring that the environment and landscapes are taken into account in harmony with economic, social and cultural development" (ICZM Protocol, art. 5).

In addition, the Protocol provides, for the first time, a common geographical criterion for the definition of coastal zones. Contrary to a common perception of the coastal zone as only the landward part from the coastline, the definition provided by the Protocol (art. 3) clearly includes the marine component as well; the coastal zone is the area between:

- the seaward limit of the coastal zone, which shall be the external limit of the territorial sea of parties; and

- the landward limit of the coastal zone, which shall be the limit of the competent coastal units as defined by the parties.

ICZM is therefore depicted as an integrated management approach, acknowledging that the coastal area is a whole system formed by both its land and sea components, with interdependent human uses and coastal resources. It, therefore, implies taking into account the interrelationships that exist between coastal uses and the environment they potentially affect. As elaborated within MedOpen, a permanent virtual training course on coastal management in the Mediterranean, ICZM requires integration at different levels, that is, across zones, time, sectors and disciplines. Still according to the Protocol, ICZM calls for reinforcement of institutional coordination, integration of sectoral policies and management approaches, as well as adoption of a participatory process facilitating horizontal and vertical dialogue, agreements and compromises between all parties involved in the use and management of coastal resources. There is no uniform approach to coastal management, and therefore there is no single way to apply ICZM in the Mediterranean. The experiences vary, reflecting the diversity of geographic conditions, policy priorities and specific concerns related to coastal areas. Therefore, agreed principles and methodological approach need to be respected, but also adapted to the country's national and local contexts.

While MSP is not expressly mentioned in the ICZM Protocol and can be considered a relatively new term within the frame of the Barcelona 
Convention, the above makes clear that planning of marine space is a concept already taken on board by the Protocol. Specifically, spatial planning of the coastal zone is mentioned by the Protocol, with the sea clearly referred to as a component of the coastal zone.

As reported in the MAP Mid-Term Strategy 2016-2021 (UNEP(DEPI)/ MED IG.22/28), the contracting parties of the Barcelona Convention at their $18^{\text {th }}$ Ordinary Meeting (December 2013, Istanbul, Turkey) recommended to strengthen MAP activities on MSP as part of ICZM, in order to contribute to the GES of the Mediterranean Sea, investigate in more detail connections between land and sea areas and propose coherent and sustainable land and sea-use planning. Moreover, the opportunity to apply MSP is mentioned several times in the Mediterranean Strategy for Sustainable Development (MSSD) 2016-2025 (UNEP/MAP, 2016) and, in particular, under MSSD Objective 1, strategic direction 1.2: "Establish and enforce regulatory mechanisms, including Maritime Spatial Planning, to prevent and control unsustainable open ocean resource exploitation". Given these premises and following two years of work coordinated by MAP Priority Actions Programme Regional Activity Centre (PAP/RAC), the $20^{\text {th }}$ Ordinary Meeting of the contracting parties to the Barcelona Convention, held in December 2017 in Tirana (Albania), adopted the "Conceptual Framework for Marine Spatial Planning" in the Mediterranean Sea (UNEP(DEPI)/MED IG.23/23). This is recognised as a guiding document to facilitate the introduction of MSP under the Barcelona Convention and, in particular, link it to ICZM, as well as to provide a common context to contracting parties for implementing MSP in the Mediterranean Region.

MSP, compared to land planning, is a fairly new and emerging process in the Mediterranean Region. In general, the process is at its initial stage and is highly influenced by differences among countries. These particularly relate to their institutional and legal framework and to some extent the availability of a reliable knowledge base (Policy Research Corporation 2011). The EU Directive on MSP (Directive 2014/89/EU) (EC 2014) is a key enabling factor (Zerkavi 2015) that has triggered concrete actions towards MSP implementation in EU member countries. All EU countries in the Mediterranean have finalised the transposition of the MSP EU Directive into national legislation and identified the competent MSP national authorities. Coordination mechanisms exist or are being created to improve cross-sector integration within MSP, and EU countries are busy developing other MSP-related activities, such as data collection and structuring, elaboration of guidelines, development of MSP methodologies, stocktaking of maritime uses and activities, elaboration of overarching vision/strategic elements and/or identification of the number 
of expected MSP plans and related geographic scope. Some initial actions have also been taken in some non-EU countries - for example, the advisory/ strategic level "Israel Marine Plan" (Portman 2015) or the design and testing of a methodology for marine vulnerability assessment based on EcAp in Boka Kotorska Bay (Montenegro) with the explicit aim of supporting MSP (see Sect. 4). Nevertheless, MSP initiatives are still unbalanced between the two shores (northern and southern) of the Mediterranean Sea.

The Mediterranean context can rely on a wide number of cross-border projects—a few of them also involving non-EU countries-focusing on MSP or indirectly dealing with related aspects (e.g. MEDTRENDS, SHAPE, ADRIPLAN, SUPREME, MSP Med-Paving the Road to MSP in the Mediterranean, THAL-CHOR, SIMWESTMED and POCTEFEXALBORÁN “Cross-border Space of Nature Shared Management"). These projects have delivered a valuable set of MSP practices and tools.

Together with the EU Directive on MSP, the Conceptual Framework for MSP is expected to support dissemination of the MSP concept and further foster its implementation in the Mediterranean Sea in close interaction with ICZM.

\section{$3 \quad$ Linking ICZM and MSP: The Importance of LSI in the Mediterranean Basin}

In the Mediterranean context, there is an evident overlap of the geographical scope of ICZM, as defined by the Protocol on ICZM, and MSP as defined by Directive 2014/89/EU (EC 2014): both include the territorial sea. From this perspective, MSP can be seen as one of the main tools for implementing ICZM in the marine part of the coastal zone, also to avoid this overlap becoming an obstacle for their joint implementation. Considering the definition of the coastal zones in the ICZM Protocol (see Sect. 2), almost all other Protocols of the Barcelona Convention are related to this in one way or another. ICZM can therefore support the implementation of several of these Protocols; vice versa, the relevant objectives and provisions of these Protocols should be taken into account in all ICZM projects, plans and strategies. Given these links, the application of MSP within the framework and the geographic scope of the ICZM Protocol can contribute to the goals set by other protocols, as in the case of identification, planning and management of protected areas according to the Protocol concerning Specially Protected Areas and Biological Diversity in the Mediterranean (SPA/BD) or the protection of the 
Mediterranean Sea against pollution resulting from exploration and exploitation of the continental shelf and the seabed and its subsoil (referring to the so-called Offshore Protocol).

ICZM and MSP share common principles, for example, sustainable management and development of coastal-marine areas, sustainable use of natural resources, importance of stakeholder participation and so on. Figure 12.1 highlights links among the principles identified by art. 6 of the ICZM Protocol and the MSP principles first included in the EC Roadmap (EC 2008b) and subsequently embedded in the EU MSP Directive. For example, the ICZM Protocol highlights the importance of adequate and timely participation in a transparent decision-making process by stakeholders concerned with the coastal zones (principle C4), which clearly matches MSP principles M4Stakeholder participation; and M3-Developing MSP in a transparent manner.

Notwithstanding these evident commonalities, they are different processes, which need to be complementary and coherently implemented. According to the Protocol for the Mediterranean, ICZM essentially aims to ensure the sustainable management of coastal zones. It stresses the need for integration/cooperation among different governance bodies and policy sectors dealing with and active on the coast, as well as informed participation and cooperation of all stakeholders. The same can be applied to MSP as regards the sustainable management of marine areas. ICZM may result in strategies and management plans and might lead to the allocation of space to specific activities (through spatial planning), in the way that MSP does for the sea.

Both processes acknowledge the importance of applying the EcAp; Fig. 12.1 also highlights the main links between MSP/ICZM and EcAp principles (the latter as defined by UNEP/CBD/COP/5/23-Annex III).

Links between ICZM and MSP are particularly evident in the Mediterranean Sea. Some Mediterranean countries have not claimed EEZ or "derived" zones, which they might be entitled to establish under the international law (UNCLOS), while for some of the claimed EEZ or "derived" zones, full validation and implementation is still pending (Suarez de Vivero 2010; MRAG, IDDRA, and LAMANS 2013). This implies that in these countries MSP implementation focuses or will focus mainly on the territorial sea, which is also part of the geographic scope of the ICZM Protocol. Maritime activities tend to concentrate in coastal waters, and leading and emerging maritime sectors in the basin (such as shipping and port activities, aquaculture, smallscale fisheries and coastal tourism) have significant interactions with the land territory. Pure offshore activities in the Mediterranean are still limited. With 

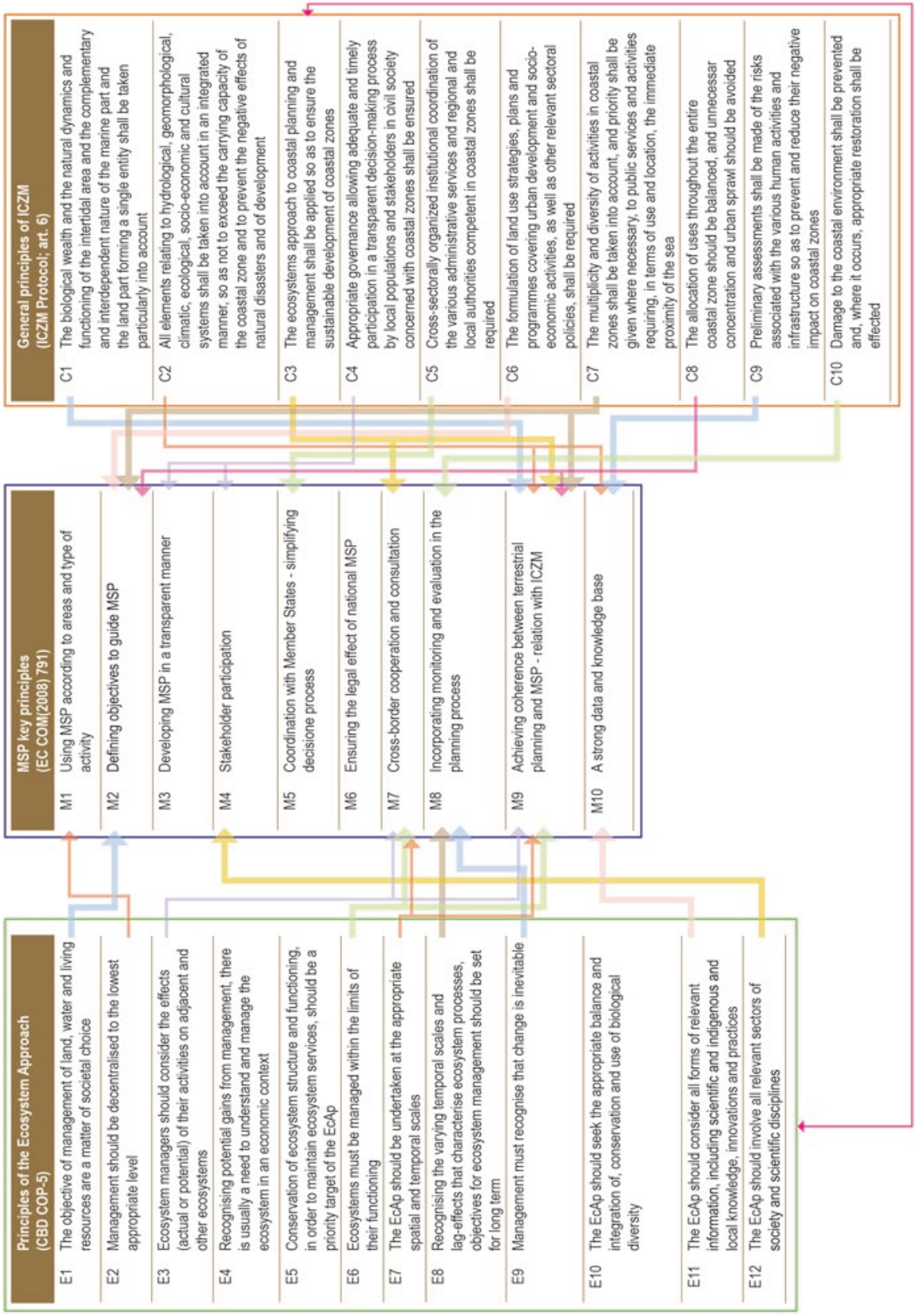
the rapid expansion of maritime economy, these connections are becoming more and more relevant (Piante and Ody 2015).

The concentration of maritime activities along the coast and relevance of LSI are also related to some geographic features of the Mediterranean basin: a large number of islands, countries with a long and indented coastline (e.g. Italy, Croatia and Greece), a high concentration of people along the coast and the presence of important land-sea transition systems (e.g. deltas of Nile, Po, Rhone and Ebro or the numerous coastal lagoons; Cataudella et al. 2015).

According to the study "ESaTDOR-European Seas and Territorial Development, Opportunities and Risks" (ESPON and University of Liverpool 2013), the marine areas close to the coasts of Spain, France, Italy, Malta, Slovenia and northern Croatia are those with greater LSI intensity in the Mediterranean and can be classified as a "regional hub" of LSI, characterised by strong land-sea interactions, high maritime activities and employment (although less than those of the European Core for LSI, i.e. the English Channel and the southern coast of the North Sea), but also significant environmental pressures. Other hotspots emerge at a more detailed scale, as in the case of the Suez Canal, Athens and Piraeus port, the Strait of Gibraltar or the coastal area of Cyprus. Great parts of the Eastern Mediterranean can be considered as area of transitional LSI intensity, with medium environmental pressures and more narrow or localised concentration of maritime economy. The Alboran Sea is characterised in a similar way. Still according to the ESaTDOR study, the southern rim of the Mediterranean is categorised as rural area (with the exception of the Strait of Gibraltar and the Suez Canal), with relatively low environmental pressure but also low levels of maritime-related activities and employment, dominated by primary production and tourism.

Most relevant LSI challenges in the Mediterranean basin are linked to both socio-economic and environmental aspects, also considering that good environmental quality plays an essential role in sustaining important economic activities, such as coastal tourism and fishery. These challenges tend to vary within the basin and are specific at sub-basin level. They include climate change adaptation and disaster risk reduction (including both natural risks, e.g. coastal erosion and flooding, and technological risks, e.g. ship collision and oil spills); planning and management of connections between land and sea-borne transportation; coastal urbanisation and littoralisation; booming of coastal tourism; land-based impacts on the marine environment such as eutrophication, chemical contamination and plastic pollution along hotspot areas; degradation/transformation of land-sea transition systems; difficulties in establishing proper protection of vulnerable and high-value coastal-marine systems; and limited connection between coastal-marine and rural development. 
All the elements described earlier call for a common implementation of ICZM and MSP, especially since they also share a number of procedural steps, for example, the creation of a strong and reliable data and knowledge base (corresponding to principles M10-C2, C9 of Fig. 12.1), the elaboration of a common and long-term vision and identification of strategic objectives (corresponding to principles M2-C6, C7), cross-sector and vertical integration (corresponding to principles M5-C5), stakeholder engagement (corresponding to principles M3, M4-C4) and so on. Indeed, the Barcelona Convention system, including its Protocols and specifically the ICZM Protocol, provides a common framework agreed at the level of the entire Mediterranean within which MSP implementation can be anchored and possibly spread beyond EU countries. From this perspective, ICZM and MSP are expected to work jointly in addressing common issues such as local socio-economic development of coastal communities or nature protection across land and sea. One of the major challenges affecting this integration is still the fragmentation of competences, which characterises both the land and sea components of the coastal area and which is even magnified when the two are considered together. The issue of competence fragmentation has been recognised as particularly relevant by the Mediterranean states since the phase of negotiation of the ICZM Protocol, when the specific request to establish appropriate coordination mechanisms to improve integration was emphasised (UNEP(DEC)MED WG. 270/5). By 2016, nearly half of the countries reported (to the ICZM Protocol/Reporting Questionnaire, based on COP Decision IG22/16) the establishment of coordination mechanisms, with a 60\% increase compared to 2013 (PAP/RAC 2013). Where existing and operationally fully implemented, these mechanisms could provide a suitable platform for coordinated governance with MSP as well.

\section{Practices from the Mediterranean Experience}

Although the process of MSP implementation is at an initial stage in most of the Mediterranean countries, a wide range of project-based experiences are available, including some demonstrating the importance of encompassing coast and sea in marine planning and management, as outlined in Sect. 3. Linking ICZM process with MSP can significantly contribute to the effectiveness of plans, leading to easier overall planning processes and improving efficiency of implementation. Experiences with ICZM provide insights on several key MSP issues like considering land-sea interactions and applying the EcAp. In many cases, cross-sector dialogue mechanisms were identified and started 
in the Mediterranean under ICZM processes, as well as multilevel cooperation experiences. Stakeholder engagement and public participation are also widely practised within ICZM. All these activities can be efficiently capitalised on within MSP. Some examples of Mediterranean practices are illustrated in this section.

Applying the EcAp. As outlined in Sect. 2, the EcAp represents a framing element for ICZM in the Mediterranean. The Montenegrin experience on Boka Kotorska Bay is a good example for how this approach and related indicators can provide a basis for the MSP process. A pilot study was developed within the Project "Defining the methodological framework for marine spatial planning in Boka Kotorska Bay (Montenegro)" (PAP/RAC and MSDT 2017), focusing on Boka Kotorska Bay, which is one of the most vulnerable zones of the Montenegrin coastal area. The pilot study designed and tested an EcAp-based methodology for marine vulnerability assessment, considering the EcAp Ecological Objectives and using related EcAp indicators. The potential use of this approach to inform the MSP and ICZM processes was also tested. The EcAp-based vulnerability assessment included three main steps:

- Identification and mapping of data related to EcAp indicators, including indicators of the environmental state of the marine and coastal area (biodiversity and landscape features, such as habitat distributional range, population abundance of selected species and alike) and indicators of existing pressures (e.g. eutrophication, contamination, physical disturbance of the coastline).

- Attribution of values to the current state (i.e. value index) and pressures on the marine areas (i.e. impact index). By using different criteria (e.g. conservation status, rareness, endemism), the value index is applied to different components of the environment. The impact index reflects the intensity of the impact on the marine environment and is defined based on criteria related to exposure to and sensitivity of the marine environment to the pressures coming from existing human activities.

- Assessment of vulnerability, which depends on the current state of the marine environment (value index), the current intensity of pressures (impact index), characteristics of future activities and resilience of the marine environment to future activities (i.e. its capacity to absorb additional pressures). Based on expert opinion on the resilience of the marine environment to each individual future activity, a vulnerability value was assigned on a scale of 1-10 for each spatial unit. 
Results of the vulnerability assessment pointed out the areas where proper management of coastal and maritime activities is needed, e.g. in terms of relocation of specific activities and/or the need to seek alternative solutions for marine uses (Fig. 12.2). The results of the vulnerability assessment can also underpin the identification of technological improvement needs or other measures needed to reduce the impacts of specific activities on the marine environment.

Engaging stakeholders. The Cypriote MSP pilot experience elaborated in 2014-2015 for the coastal and marine area of Limassol (south of Cyprus) in the framework of the project Cross-border Cooperation for Maritime Spatial Planning Development THAL-CHOR $(\Theta \mathrm{A} \Lambda-\mathrm{X} \Omega \mathrm{P})^{1}$ provides an example of joint planning for land/coastal-related activities and maritime sectors, which was based on stakeholder engagement across the entire process. The pilot experience developed tailored tools in order to communicate spatial information relevant for the plan and facilitate informed dialogue and cooperation. The process faced issues of great interest for ICZM and MSP and their integration: resolution of spatial conflicts between different uses of the sea and coastal areas, better coordination between different stakeholders and creation of conditions for achieving sustainable development in line with the strategy "Europe 2020" were among THAL-CHOR objectives.

The analysis performed in the MSP pilot experience identified a high concentration of coastal and maritime activities in the Limassol area, including shipping, ports activities, fisheries, aquaculture, tourism, military use, cables and pipelines, and securing freshwater supply. Oil and gas exploitation and offshore renewable energy production were also considered as potential future activities. Conflicts and compatibilities among these activities were analysed. Spatial data were structured in a common Web-GIS system, which was made available via the THAL-CHOR project website to share results and support stakeholder engagement. Great emphasis was placed on stakeholder engagement during pilot plan elaboration: results of the conflict analysis were shared with local stakeholders through consultation workshops. Despite the Limassol plan being a pilot MSP plan and, therefore, not legally binding, it represents a valuable MSP example embedding relevant aspects of ICZM. This MSP pilot experience and similar ones conducted in Lesvos and Rhodes (Greece) in the frame of the same project enabled designing and testing a methodology for the development of MSP plans.

Promote institutional coordination and integrated governance. The Coastal Area Management Programme (CAMP; UNEP/MAP 1999) funded

\footnotetext{
${ }^{1}$ www.mspcygr.info; accessed on 22 June 2018.
} 


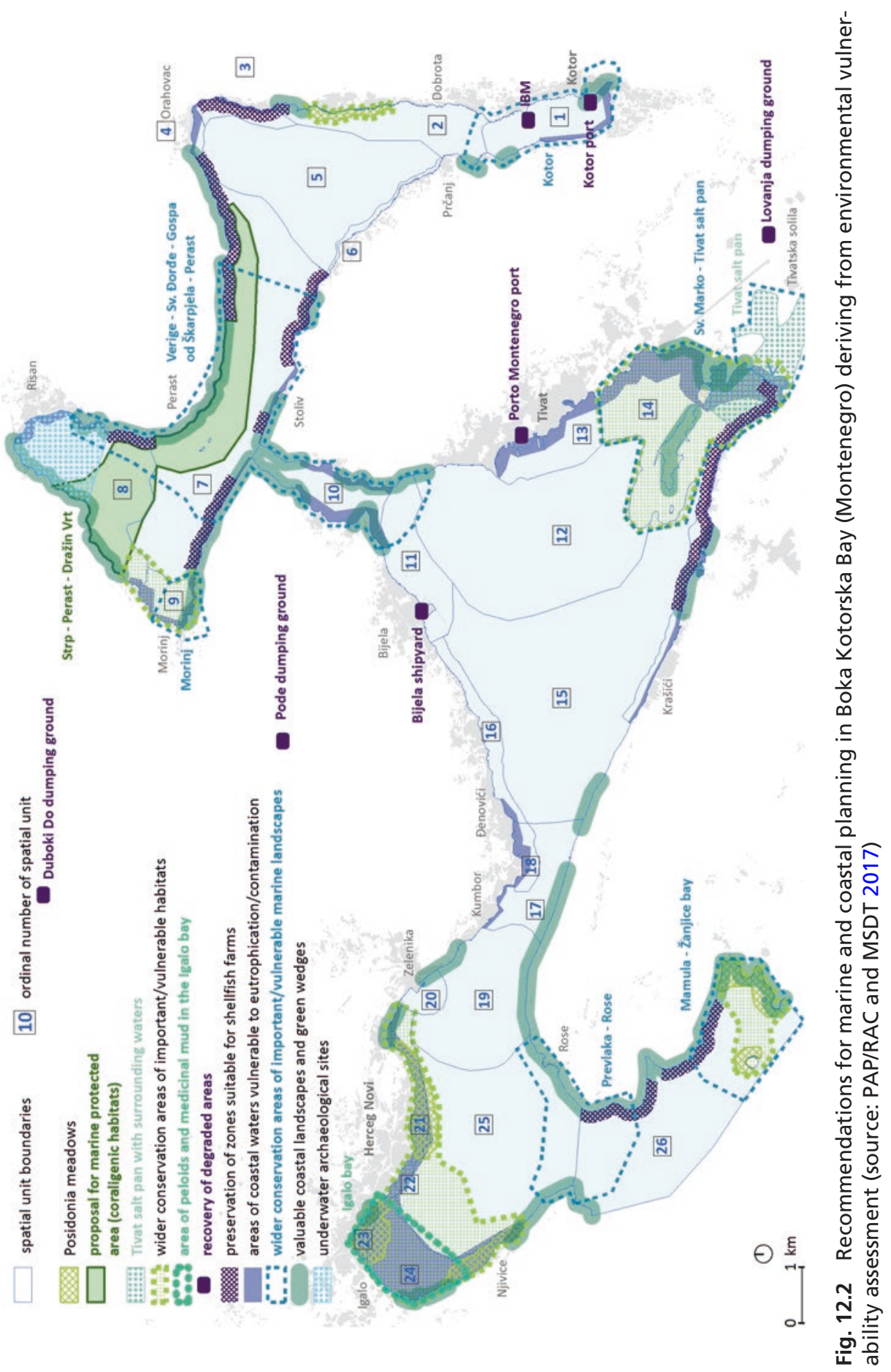


by MAP, with co-financing from the respective countries, and coordinated by $\mathrm{PAP} / \mathrm{RAC}$, is oriented at the implementation of practical coastal management projects in selected Mediterranean coastal areas, applying ICZM as a major tool. CAMP projects have been implemented in most Mediterranean countries (UNEP/MAP/PAP 2015).

The CAMP project implemented in France (2014-2017) focused on the Var Department in Provence-Alpes-Côte d'Azur Region, covering an area of about $6,000 \mathrm{~km}^{2}$, with $432 \mathrm{~km}$ of coastline, including ten islands and islets (70 km are occupied by military establishments, $40 \mathrm{~km}$ are urban areas and ports, while $92 \mathrm{~km}$ are beaches and $230 \mathrm{~km}$ are rocky shores). Objectives of the project were to identify and support local initiatives contributing to ICZM Protocol implementation; to facilitate and encourage more effective and coherent governance of the Var territory with its multiple layers of policies and regulations at different scales; and to develop transferable methodologies which can benefit other territories. Specifically, the actions of the project included:

- setting up of a consultative body, named Terre et Mer Var Forum, organising informal mediation meetings that facilitated exchanges between the different stakeholders of the Var coastal area;

- development of an evaluation study of sea and coastal management and planning policies in the Var, with regard to their relevance for the implementation of the ICZM Protocol; and

- development of operational actions, in partnership with civil society and institutions. These included concrete initiatives such as the management of ports and navigation basins but also educational initiatives aiming at developing a cultural "brand" for the Mediterranean islands (named "Archipelago of excellence"), like, for example, the production of films on some of the small Mediterranean islands and their surrounding maritime area, for example, the Specially Protected Areas of Mediterranean Importance (SPAMI), namely, the Port-Cros National Park and the archipelago of Embiez/Six-Fours.

The Terre et Mer Var Forum was set up to be a place of mediation and governance at the local scale of the Var Department, supporting the actions of key local actors such as the Conservatoire du littoral. The latter is a state institution managing public coastal land for conservation purposes and ensuring free access to the public. Biodiversity, aesthetics and cultural identity of the littoral are protected, also with direct engagement of local communities and associations. The Forum was conceived as a laboratory to stimulate a dynamic dia- 
logue among coastal stakeholders, to advance in the development of an integrated governance mechanism and to highlight the successes and difficulties encountered in the implementation of ICZM policies. Although created within the CAMP France project, the Forum continues to operate, facilitating discussions related to coastal and marine management stimulated by other projects as well, like SIMWESTMED.

Ensure integrated managed development of coastal and marine areas. The proposals for ICZM-MSP for the Emilia Romagna Region (Italy) formulated within the Italian National Project RITMARE (Barbanti and Perini 2018) provide an example of integrated scenario analysis for the coast and the sea, aiming to address and guide the growth and development of coastal and maritime activities. The analysis consisted of the following steps: (1) update of existing assessments; (2) analysis of expected trends of maritime activities in the area; (3) analysis of conflicts, synergies and cumulative impacts; (4) definition of a common vision and related objectives; (5) identification of a portfolio of spatial measures; and (6) elaboration of an integrated scenario. Sectors, Departments and Services of the Emilia Romagna Region were engaged along the different steps.

A vision was developed where tourism is seen as pivotal for economics, ensuring it also acts as promoter of other economic sectors and does not compromise natural resources, thus supporting the regional economy. A portfolio of spatial measures was identified referring to six major uses: coastal defence, decommissioning of oil and gas offshore platforms, development of offshore wind farms, fishery and aquaculture, environmental protection and management of areas used for military purpose. The set of measures has the following objectives:

- Sustainable development through establishment of new uses, promoting Blue Growth in the area by overcoming existing barriers but safeguarding the uses already in place

- Reduction of conflicts and increase of synergies among uses

- Reduction of environmental impacts, particularly in the area between 0 and $6 \mathrm{~nm}$, and increase the level of protection of relevant habitats and species

An integrated "managed development" scenario was finally developed which considers all the measures implemented at the same time and aims to pursue the above objectives in an integrated way. This led to an assessment of the possible overall reduction in use conflicts and cumulative impacts as a result of applying the proposed measures. 
Integrate different specific spatial policy for coastal and marine areas. The variety and heterogeneity of coastal and marine environments in the Mediterranean call for a tailored approach for the specificities of different areas. In order to enable the implementation of specific policy measures, the Israel Marine Plan (Portman 2015), an initiative of a group of researchers and planners at the Faculty of Architecture and Town Planning's Center for Urban and Regional Studies at the Technion, ${ }^{2}$ proposes to divide Israeli marine space into five functional marine areas that are spatially distinguished from each other. The distinction between the functional marine areas lies within the priorities and reciprocal relationships between uses or actions in each of them. Each of the marine areas is therefore an exploration area that offers a variety of opportunities and yet enables managing conflicts and attaining synergies in accordance with the goals set by the plan. Decisions made according to the distinctive guidelines for each one of the marine areas would thus enable the social, economic and environmental functioning of the entire marine space. The areas are identified as follows:

- "Marine protected areas" considered the most protected areas among all those included in the plan. the areas. They are the main exploration areas for designations related to nature and landscape preservation and protection. The policy proposed here is a proactive policy for high priority location and approval of marine protected areas at various levels.

- "Marine shared areas" spread out between the "horizon line" as delineated in the plan and the boundary of the coastal shipping corridor that stretches to its west, and between strips of sections of the "Marine protected area". They are development-oriented areas and are the main exploration areas for intervention and development designations. Here, too, a proactive policy is suggested for locating, at a high priority, sustainable human usages.

- "Marine horizon areas" are visible from densely populated urban shores and extend in front of them; therefore, they are very sensitive from a social point of view and constitute a significant public resource. Decision-makers will act to preserve an open landscape, to decrease the risk from existing and future infrastructure facilities and to utilise this area for purposes of leisure and recreation. This typology of area also includes vulnerable habitats and a main concentration of heritage values linked with the shore; it also includes harbours and other coastal infrastructures. Proximity to the shore also implies proximity to sources of pollution.

\footnotetext{
${ }^{2}$ msp-israel.net.technion.ac.il; accessed on 22 June 2018.
} 
- "Marine shared-protected area" spreads over the back of the horizon space and between the strips of the marine protected area up to the edge of the continental slope. The policy proposed for this area is a reactive policy intended to preserve this area as an open marine space and to view it as a secondary exploration area for additional protected areas, as well as a future secondary exploration area for limited constrained human uses.

- "Deep sea area" spreads out from the edge of the continental slope up to the limit of the economic waters. The proposed policy for this area will give high priority to exploration intended for human usage.

\section{Ways Forward}

The EU MSP Directive is one of the main enabling factors for MSP implementation in some of the Mediterranean Sea countries. However, its application is limited to EU member states. Nevertheless, the principle of sincere cooperation, including cooperation with non-EU countries, is fundamental for the implementation of such a Directive. Embedding MSP in the ICZM process defined by the Barcelona Convention can provide a wider, common and legally based framework for MSP implementation in the entire Mediterranean. From this perspective, the adoption of the Conceptual Framework for Marine Spatial Planning in the Mediterranean Sea represents an initial step in this direction. Integration of ICZM and MSP is an important component of the activities that MAP is carrying out in the biennium 2018-2019. This specifically includes the ongoing elaboration of the Common Regional Framework on ICZM, within which the Conceptual Framework for MSP is to be integrated. Together with the essential role the EU MSP Directive plays for the EU countries, this process is expected to contribute to the dissemination and implementation of the MSP concept in the coming years.

The importance of applying integrated ICZM-MSP in the Mediterranean Sea also stems from the high relevance of environmental, social and economic land-sea interactions which characterise this sea basin. Indeed, integrating ICZM and MSP would also seem highly relevant in other semi-enclosed basins, such as, in particular, the Black Sea (Golumbeanu and Nicolaev 2015).

Notwithstanding the relevance of a pan-Mediterranean approach to MSP, it is also important to acknowledge that this sea basin is characterised by subregional specificities. As highlighted by the Conceptual Framework for MSP, a multi-scalar approach is recommended to tailor a common approach to specific characteristics. The scale of the entire Mediterranean might be 
relevant for defining common strategic goals and approaching transboundary challenges; some of them might assume specific significance at the subregional level. With the gradual introduction of MSP, the Barcelona Convention can provide an institutional framework for cooperation in the Mediterranean also for marine planning and management. At the same time, at the subregional level, other cooperation mechanisms can play a relevant role, for example, the EU Strategy for the Adriatic Ionian Region (EUSAIR). The multi-scalar approach is completed by the national and, in some cases, subnational levels which are expected to implement the statutory MSP processes.

Although challenging, the establishment of new EEZs and the full application of existing ones would extend the area of MSP implementation, providing opportunities for both the managed exploitation of marine resources and space as well as for improved conservation (Katsanevakis et al. 2015). The resolution of pending disputes on maritime borders would also help in defining a clear legal basis for MSP implementation in the Mediterranean.

Project-based experience on (cross-border) MSP in the Mediterranean is rather rich and keeps growing, focusing also on integration between marine and coastal planning. This has delivered a variety of practices (such as datasharing infrastructures, tools, methodologies, handbooks, guidelines, recommendations and pilot plans) that can be transferred and used in the formal MSP processes, considering the necessary phases of testing and adaptation. Although the uptake of project outcomes still needs to be improved, the main challenge lies in the unbalanced distribution of experiences between EU and non-EU countries, also affecting data availability and accessibility. Some recently started or upcoming initiatives will contribute to filling this gap, for example, the MSP project in Albania and Montenegro (Implementation of the EcAp in the Adriatic Sea through MSP) funded by the Global Environmental Facility, which was officially launched in May 2018, or the pilot project on cross-border MSP to be launched in the Western Mediterranean according to the "Joint Roadmap to accelerate Maritime/Marine Spatial Planning processes worldwide" adopted on 24 March 2017 by the Intergovernmental Oceanographic Commission of UNESCO and the Directorate-General for Maritime Affairs and Fisheries of the European Commission. CAMP projects implemented up to now (18 plus 1 in preparation, each in a different country) have resulted in the successful spread of the ICZM concept around the entire Mediterranean and in testing the application of different provisions of the ICZM Protocol. A second round of CAMP projects could focus on integrating spatial planning of the sea with the overarching ICZM frame- 
work at the national or subnational scale, thus further contributing to increased capacity building in MSP in non-EU countries.

Acknowledgements The authors acknowledge that part of the contents of this chapter derives from their contribution to the ongoing EU co-funded SUPREME and SIMWESTMED projects. In addition, the authors thank Ms Željka Škaričić (PAP/ $\mathrm{RAC})$ and Mr Sylvain Petit (PAP/RAC) for their suggestions and final reading of the chapter. We are grateful to the project "Economy of maritime space" funded by the Polish National Science Centre for contributing the Open Access fee for this chapter and facilitating our discussions and preparation of the book.

\section{References}

Barbanti, A., \& Perini, L. (Eds.). (2018). Between Land and Sea: Analysis and Proposals for Maritime Spatial Planning in Emilia-Romagna Region (in Italian: Fra la terra e il mare: Analisi e proposte per la pianificazione dello Spazio Marittimo in Emilia Romagna). https://doi.org/10.5281/zenodo.1184364.

Cataudella, S., Crosetti, D., \& Massa, F. (2015). Mediterranean Coastal Lagoons: Sustainable Management and Interactions Among Aquaculture, Capture Fisheries and the Environment. General Fisheries Commission for the Mediterranean, Food and Agriculture Organisation of the United States, Studies and Reviews No. 95. Retrieved from http://www.fao.org/3/a-i4668e.pdf.

Chevalier, C. (2004). Governance in the Mediterranean Sea. Legal Regime and Prospective. IUCN Centre for Mediterranean Cooperation. Retrieved from https://cmsdata.iucn.org/downloads/legalspects_en_1.pdf.

Cinnirella, S., Sardà, R., Suárez de Vivero, J. L., Brennan, R., Barausse, A., Icely, J., Luisetti, T., March, D., Murciano, C., Newton, A., O'Higgins, T., Palmeri, L., Palmieri, M. G., Raux, P., Rees, S., Albaigés, J., Pirrone, N., \& Turner, K. (2014). Steps Toward a Shared Governance Response for Achieving Good Environmental Status in the Mediterranean Sea. Ecology and Society, 19(4), 47. https://doi. org/10.5751/ES-07065-190447.

DOALOS-Division for Ocean Affairs and the Law of the Sea, Office of Legal Affairs, United Nations Secretariat. Maritime Space: Maritime Zones and Maritime Delimitation. Retrieved June, 2018, from http://www.un.org/Depts/ los/LEGISLATIONANDTREATIES/index.htm.

EC. (2008a). Directive 2008/56/EC of the European Parliament and of the Council of 17 June 2008, establishing a framework for community action in the field of marine environmental policy (Marine Strategy Framework Directive). Retrieved from https://eur-lex.europa.eu/legal-content/EN/TXT/PDF/?uri=CELEX:32008 L0056\&from=EN. 
EC. (2008b). EC COM(2008)791 final. Communication from the Commission: Roadmap for Maritime Spatial Planning: Achieving Common Principles in the EU. Retrieved from https://eur-lex.europa.eu/LexUriServ/LexUriServ.do?uri=COM: 2008:0791:FIN:EN:PDF.

EC. (2014). Directive 2014/89/EU of the European Parliament and of the Council of 23 July 2014 Establishing a Framework for Maritime Spatial Planning. Retrieved from https://eur-lex.europa.eu/legal-content/EN/TXT/PDF/?uri=CEL EX:32014L0089\&from=EN.

ESPON \& University of Liverpool. (2013). ESaTDOR European Seas and Territorial Development, Opportunities and Risks. Applied Research 2013/1/5. Final Report, Version 15/4/2013. Retrieved from https://www.espon.eu/programme/projects/ espon-2013/applied-research/esatdor-european-seas-and-territorial-development.

Golumbeanu, M., \& Nicolaev, S. (Eds.). (2015). Study on Integrated Coastal Zone Management. 454 pp. Ex Ponto Publishing House, 2015. ISBN: 978-606-598-397-7

Katsanevakis, S., Levin, N., Coll, M., Giakoumi, S., Shkedi, D., Macklewotrh, P., Levy, R., Velegrakis, A., Koutsoubas, D., Caric, H., Brokovich, E., Ozturk, B., \& Kark, S. (2015). Marine Conservation Challenges in an Era of Economic Crisis and Geopolitical Instability: The Case of the Mediterranean Sea. Marine Policy, 51, 31-39. https://doi.org/10.1016/j.marpol.2014.07.013.

MRAG, IDDRA, \& LAMANS. (2013). Costs and Benefits Arising from the Establishment of Maritime Zones in the Mediterranean Sea. Final Report. Retrieved from https://ec.europa.eu/maritimeaffairs/sites/maritimeaffairs/files/docs/body/ maritime-zones-mediterranean-report_en.pdf.

PAP/RAC. (2013). Ensuring Appropriate Coordination: An Explanatory Report of Article 7 of the ICZM Protocol. Project SHAPE. Priority Actions Programme Regional Activity Centre, Split. 34 pp. Retrieved from https://www.pap-thecoastcentre.org/pdfs/explanatory_article_7_outline_final_feb13.pdf.

PAP/RAC \& MSDT. (2017). Vulnerability Assessment of the Marine Environment in the Boka Kotorska Bay. Methodological Guidelines (Analiza ranjivosti morske sredine u Bokokotorskom zalivu. Metodološke smjernice). Priority Actions Programme Regional Activity Centre; Ministry of Sustainable Development and Tourism (Montenegro). Podgorica, 2017.

Piante, C., \& Ody, D. (2015). Blue Growth in the Mediterranean Sea: The Challenge of Good Environmental Status. MEDTRENDS Project. WWF-France. 192 pp.

Policy Research Corporation. (2011). Exploring the Potential for Maritime Spatial Planning in the Mediterranean Sea. Final Report. Study Carried Out on Behalf of the European Commission Directorate-General for Maritime Affairs and Fisheries. Retrieved from https://ec.europa.eu/maritimeaffairs/documentation/studies/ study_msp_med_en.

Portman, M. E. (2015). Marine Spatial Planning in the Middle-East: Crossing the Policy Planning Divide. Marine Policy, 61(2015), 8-15. https://doi.org/10.1016/j. marpol.2015.06.025. 
Rochette, J., Wemaëre, M., Billé, R., \& du Puy-Montbrun, G. (2012). A Contribution to the Interpretation of Legal Aspects of the Protocol on Integrated Coastal Zone Management in the Mediterranean. UNEP/MAP, Priority Actions ProgrammeRegional Activity Centre, Split, 72 p. + annexes. Retrieved from https://www. pap-thecoastcentre.org/regional_medpartnership_workshop/documents/ ICZM\%20Protocol_Legal\%20aspects.pdf.

Saliot, A. (Ed.). (2005). The Mediterranean Sea. The Handbook of Environmental Chemistry. Springer-Verlag Berlin Heidelberg. 410 pp.

Suarez de Vivero J. L. (2010). Jurisdictional Waters in the Mediterranean and Black Seas. Study Carried Out for European Commission Directorate-General for Internal Policies of the Union-Policy Department B: Structural and Cohesion Policy_Fisheries, 134 pp.

UNEP(DEC)MED WG. 270/5. Draft Protocol on Integrated Coastal Zone Management in the Mediterranean. Meeting of the MAP Focal Points. Athens, Greece, 21-24 September 2005. Retrieved from https://wedocs.unep.org/bitstream/handle/20.500.11822/5515/05wg270_5_eng.pdf? sequence=1 \&isAllowe $\mathrm{d}=\mathrm{y}$.

UNEP(DEPI)/MED IG.21/9-Annex II-Thematic Decisions. Decision IG.21/3 on the Ecosystems Approach including adopting definitions of Good Environmental Status (GES) and targets. Retrieved from https://wedocs.unep. org/rest/bitstreams/8206/retrieve.

UNEP(DEPI)/MED IG.22/28. Decision IG.22/1: UNEP/MAP Mid-Term Strategy 2016-2021. Retrieved from https://wedocs.unep.org/rest/bitstreams/8364/ retrieve.

UNEP(DEPI)/MED IG.23/23. Decision IG.23/7: Implementation of the Integrated Coastal Zone Management Protocol: Annotated Structure of the Common Regional Framework for Integrated Coastal Zone Management and Conceptual Framework for Marine Spatial Planning. Retrieved from http://wedocs.unep.org/ bitstream/id/74412/17ig23_23_2307_eng.pdf.

UNEP/CBD/COP/5/23-Annex III. Report of the Fifth Meeting of the Conference of the Parties to the Convention on Biological Diversity. Annex III: Decisions Adopted by the Conference of the Parties to the Convention on Biological Diversity at its Fifth Meeting, Nairobi, 15-16 May 2000. Retrieved from https:// www.cbd.int/doc/meetings/cop/cop-05/official/cop-05-23-en.pdf.

UNEP/MAP. (1999). Formulation and Implementation of CAMP Projects: Operational Manual. MAP-PAP/RAC, Athens-Split. 86pp. Retrieved from https://pap-thecoastcentre.org/itl_public.php?public_id=28.

UNEP/MAP. (2015). The Mediterranean Action Plan. Barcelona Convention and its Protocols. Overview. United Nations Environment Programme/Mediterranean Action Plan. Retrieved from https://wedocs.unep.org/rest/bitstreams/1298/retrieve. UNEP/MAP. (2016). Mediterranean Strategy for Sustainable Development 2016-2025. Valbonne: Plan Bleu, Regional Activity Centre. Retrieved from https://planbleu. org/sites/default/files/upload/files/MSSD_2016-2025_final.pdf. 
UNEP/MAP. (2017). 2017 Mediterranean Quality Status Report. UNEP(DEPI)/ MED IG.23/Inf.10/rev.1.

UNEP/MAP/PAP. (2008). Protocol on Integrated Coastal Zone Management in The Mediterranean. Priority Actions Programme-Regional Activity Centre, Split, 118 pp. Retrieved from https://www.pap-thecoastcentre.org/pdfs/Protocol_publikacija_May09.pdf.

UNEP/MAP/PAP. (2015). Assessment of Coastal Area Management programme (CAMP) Projects. Mediterranean Action Plan, Priority Actions Programme Regional Activity Centre. Split, Croatia. 76 pp. Retrieved from https://pap-thecoastcentre.org/itl_public.php?public_id=28.

UNEP/MAP-Plan Bleu. (2009). State of the Environment and Development in the Mediterranean - 2009. Plan Bleu, Athens, Greece, 200 pp. Retrieved from https:// planbleu.org/sites/default/files/publications/soed2009_en.pdf.

Zerkavi, A. (2015). Introducing Maritime Spatial Planning Legislation in the EU: Fishing in Troubled Waters? Maritime Safety and Security Law Journal, 1/2015, 95-114. Retrieved from http://www.marsafelawjournal.org/wp-content/uploads/ 2015/09/Issue1_Zervaki_Article.pdf.

Open Access This chapter is licensed under the terms of the Creative Commons Attribution 4.0 International License (http://creativecommons.org/licenses/by/4.0/), which permits use, sharing, adaptation, distribution and reproduction in any medium or format, as long as you give appropriate credit to the original author(s) and the source, provide a link to the Creative Commons licence and indicate if changes were made.

The images or other third party material in this chapter are included in the chapter's Creative Commons licence, unless indicated otherwise in a credit line to the material. If material is not included in the chapter's Creative Commons licence and your intended use is not permitted by statutory regulation or exceeds the permitted use, you will need to obtain permission directly from the copyright holder.

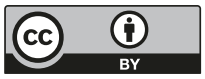

